\title{
Investigando concepções de educação em saúde de estudantes universitários de Ciências Biológicas relacionadas ao controle do Aedes aegypti
}

Andréia Guerra Pimentel ${ }^{1}$, Suzete Araujo Oliveira Gomes ${ }^{2}$, Ana Paula Massadar Morel $^{3}$, Gutemberg Gomes Alves ${ }^{4}$, Carolina Nascimento Spiegel ${ }^{5}$

\begin{abstract}
Resumo
Estratégias tradicionais, baseadas em inseticidas e comportamentos individuais, não têm se mostrado suficientes no controle de doenças relacionadas ao Aedes aegypti. Reflexões da Educação Popular em Saúde que ultrapassem aspectos biomédicos e englobem fatores sociais, econômicos e políticos devem ser consideradas no controle e estar presentes na formação de profissionais da área. Neste trabalho foram investigadas as concepções de educação em saúde de alunos de Ciências Biológicas de duas universidades públicas, no início e no final da graduação, por meio de questionários sobre estratégias para controlar doenças transmitidas pelo vetor e sobre o papel do professor de Ciências/Biologia na promoção da saúde. Prevaleceram respostas incluindo a educação sanitária e a valorização de medidas de monitoramento, conscientização e prevenção contra criadouros do mosquito. Poucas respostas incluíram noções de educação popular na demanda por transformações na sociedade e a garantia de direitos como saneamento básico, meio ambiente equilibrado e serviços de saúde. Predominou a visão do professor como transmissor de conhecimentos e não como motivador de diálogos articulando a questão da dengue com os determinantes sociais da saúde. O enfoque na educação sanitária na concepção dos alunos faz refletir sobre a necessidade de maiores aprofundamentos sobre educação popular na formação de biólogos.
\end{abstract}

\section{Palavras-chave}

Educação em saúde. Dengue. Formação em Ciências Biológicas. Educação popular. Educação sanitária.

\footnotetext{
${ }^{1}$ Doutoranda em Ciências e Biotecnologia pela Universidade Federal Fluminense, Rio de Janeiro, Brasil; tutora presencial da Fundação Centro de Ciências e Educação Superior a Distância do Estado do Rio de Janeiro, Brasil. E-mail: andreiaguerrapimentel@gmail.com.

${ }^{2}$ Doutora em Biologia Parasitária pela Fundação Oswaldo Cruz, Rio de Janeiro, Brasil, com estágio pós-doutoral em Bioquímica Celular pela Universidade Federal do Rio de Janeiro, Brasil; professora associada do Departamento de Biologia Geral da Universidade Federal Fluminense, Rio de Janeiro, Brasil. E-mail: suzetearaujo@id.uff.br.

${ }^{3}$ Doutora em Antropologia Social pela Universidade Federal do Rio de Janeiro, Brasil; professora da Faculdade de Educação da Universidade Federal Fluminense, Rio de Janeiro, Brasil. E-mail: anamoreloemail@gmail.com.

${ }^{4}$ Doutor em Química Biológica pela Universidade Federal do Rio de Janeiro, Brasil; professor associado do Departamento de Biologia Celular e Molecular da Universidade Federal Fluminense, Rio de Janeiro, Brasil. Email: gutopepe@yahoo.com.br.

5 Doutora em Biologia Celular e Molecular pela Fundação Oswaldo Cruz, Rio de Janeiro, Brasil; professora Associada do Departamento de Biologia Celular da Universidade Federal Fluminense, Rio de Janeiro, Brasil. E-mail: carolina.spiegel@gmail.com.
} 


\title{
Investigating health education concepts of university students of biological sciences related to the control of Aedes aegypti
}

Andréia Guerra Pimentel ${ }^{6}$, Suzete Araujo Oliveira Gomes ${ }^{7}$, Ana Paula Massadar Morel $^{8}$, Gutemberg Gomes Alves ${ }^{9}$, Carolina Nascimento Spiegel ${ }^{10}$

\begin{abstract}
Traditional strategies, based on insecticides and individual behaviors, have not been shown as sufficient in the control of diseases related to Aedes aegypti. Insights on Popular Education in Health that go beyond biomedical aspects and include social, economic and political factors must be considered in this control and be present in the training of professionals in the area. In this work, the health education conceptions of Biological Sciences students from two public universities were investigated, at the beginning and at the end of graduation, through questionnaires regarding strategies to control vector-borne diseases and the role of the Sciences/Biology teacher on health promotion. Most answers included sanitary education and the valuing of monitoring, awareness and prevention measures against mosquito breeding sites. Few responses included notions of popular education in the demand for changes in society and the guarantee of human rights such as basic sanitation, a balanced environment and health services. The view of the teacher as a transmitter of knowledge prevailed, and not as a motivator for dialogues, who articulates the issue of dengue with the social determinants of health. The focus on sanitary education in the conception of students raises insights on the need for further studies on popular education in the training of biologists.
\end{abstract}

\section{Keywords}

Health education. Dengue. Training in Biological Sciences. Popular education. Sanitary education.

\footnotetext{
${ }^{6} \mathrm{PhD}$ student in Science and Biotechnology, Federal Fluminense University, Rio de Janeiro, Brazil; tutor at the Center for Science and Higher Education Foundation of the State of Rio de Janeiro, Brazil. E-mail: andreiaguerrapimentel@gmail.com.

$7 \mathrm{PhD}$ in Parasitic Biology, Oswaldo Cruz Foundation, State of Rio de Janeiro, Brazil, with post-doctoral internship in Cellular Biochemistry, Federal University of Rio de Janeiro, Brazil; associate professor in the Department of General Biology at Federal Fluminense University, State of Rio de Janeiro, Brazil. E-mail: suzetearaujo@id.uff.br.

${ }^{8} \mathrm{PhD}$ in Social Anthropology, Federal University of Rio de Janeiro, Brazil; professor at the Faculty of Education at Federal Fluminense University, State of Rio de Janeiro, Brazil. E-mail: anamoreloemail@ gmail.com.

$9 \mathrm{PhD}$ in Biological Chemistry, Federal University of Rio de Janeiro, Brazil; associate professor in the Department of Cellular and Molecular Biology at Federal Fluminense University, State of Rio de Janeiro, Brazil. E-mail: gutopepe@yahoo.com.br.

${ }^{10} \mathrm{PhD}$ in Cellular and Molecular Biology, Oswaldo Cruz Foundation, State of Rio de Janeiro, Brazil; associate professor in the Department of Cell Biology at Federal Fluminense University, State of Rio de Janeiro, Brazil. E-mail: carolina.spiegel@gmail.com.
} 


\section{Introdução}

As doenças causadas por patógenos transmitidos pelo Aedes aegypti, como dengue, zika e chikungunya, são graves problemas de saúde pública no Brasil, pois o número de casos aumenta a cada ano. De dezembro de 2018 a agosto de 2019 houve um aumento de 599,5\% das referidas arboviroses (BRASIL, 2019). Somente no período entre 29 de dezembro de 2019 até $1^{\circ}$ de fevereiro de 2020, foram registrados, como casos prováveis, aproximadamente 94 mil de dengue, 3.439 de chikungunya e, para a mesma data inicial até 25 de janeiro de 2020, 242 de zika. Foram registradas ainda, 93 crianças com Síndrome Congênita associada à infecção pelo vírus Zika (SCZ) (BRASIL, 2020).

Este não é um problema recente: entre 1986 e 1991, houve uma grande epidemia de dengue no município do Rio de Janeiro. Na ocasião, os serviços de saúde adotaram como estratégia de combate ao vetor o uso de inseticidas e a divulgação de informações orientando comportamentos individuais de prevenção contra a proliferação dos mosquitos (OLIVEIRA; VALLA, 2001). No entanto, por mais que se conheça o ciclo de vida do vetor, os sintomas e as formas de tratamentos das doenças para reduzir o número de casos, o conceito de saúde não pode se restringir aos aspectos biomédicos. A Comissão Nacional sobre Determinantes Sociais da Saúde (CNDSS) do Brasil considera de forma ampla o processo de saúde das populações, incluindo fatores sociais, econômicos, culturais, étnicos/raciais, psicológicos e comportamentais (BUSS; PELLEGRINI FILHO, 2006).

Para haver melhorias nas condições de saúde, é essencial a participação de toda a sociedade na luta pela garantia de direitos e na responsabilidade do cumprimento de deveres. De acordo com Rangel (2008, p. 435), a participação das pessoas é indispensável na busca por transformações no modelo de atenção à saúde "tentando-se superar os modelos hegemônicos - médico-assistencialista e o sanitarista-campanhista - para enfatizar a promoção da saúde e o conceito ampliado de saúde, a integralidade da atenção e a participação social". A autora reflete sobre a prevalência de práticas hegemônicas e de problemas relativos à educação, comunicação e participação comunitárias no controle da dengue e discute sobre modelos que orientam ações, a saber: modelo de comunicação e educação; modelo explicativo da dengue no programa de controle; e modelo de prevenção e modelo de participação. O modelo de comunicação e educação se refere à transmissão de informações e conhecimentos, visando mudanças de hábitos e comportamentos, seguindo um perfil “campanhista, pontual, descontínuo, com ênfase para situações epidêmicas, quando seria necessário que a dengue estivesse na pauta da mídia durante todo o ano" (RANGEL, 2008, p. 436). O modelo 
explicativo é focado no vetor e no combate aos criadouros. O modelo de prevenção é voltado para campanhas sanitárias de higienização para combate ao vetor, em uma perspectiva em que a responsabilidade é individual e as vítimas são culpabilizadas, pois o julgamento é que a “população é resistente, ignorante e pouco ativa na busca da melhoria de sua saúde, e no controle da dengue" (RANGEL, 2008, p. 437). E, por fim, o modelo de participação é conduzido de forma autoritária, sendo a população convocada a participar pelas "autoridades sanitárias, ou seja, a população é chamada a colaborar com a ação de inspeção sanitária" (RANGEL, 2008, p. 438).

Todos esses modelos descritos enquadram-se na concepção hegemônica de educação em saúde denominada educação sanitária. Segundo Nespoli (2016), essa concepção ganha força no Brasil, no início do século 20, no contexto de políticas higienistas focadas em aspectos biológicos e que desconsideravam aspectos sociais, culturais, econômicos e políticos no entendimento de saúde. Nesse cenário, medidas educativas deveriam servir para:

convencer as pessoas a aceitarem e participarem do controle das doenças, por meio de medidas preventivas, de profilaxia e de autocuidado, e da mudança dos hábitos e comportamentos. Foi assim que a educação sanitária se constituiu como uma forma de controle e ordenamento social, ancorada no pressuposto de que a ignorância era a principal causa das doenças. (NESPOLI, 2016, p. 47).

Nessa perspectiva, segundo Stotz (1993), a saúde é encarada como uma "escolha individual" e não como um "direito social". O autor reflete sobre a representação do doente como um sujeito que não se enquadra em um padrão de normalidade, sendo, por isso, culpado pelas doenças devido a comportamentos individuais de risco, tais como vida sedentária e consumo de substâncias potencialmente prejudiciais. Da mesma forma, nas epidemias, a culpa é atribuída a cada pessoa individualmente, não sendo consideradas como um problema coletivo:

O raciocínio vale igualmente para situações epidêmicas, como podemos observar a partir da primeira epidemia de dengue ocorrida na cidade do Rio de Janeiro, em 1987: o problema é o vizinho descuidado (geralmente uma pessoa pobre), porque não tampa os reservatórios de água para evitar a entrada e deposição dos ovos do mosquito Aedes aegypti. A falta de água corrente não entra neste raciocínio, bem como não se consideram os grandes criadouros do mosquito, a saber, os terrenos baldios, as piscinas sem tratamento, os cemitérios, os depósitos de automóveis e ferros-velhos abandonados. (STOTZ, 1993, p. 4). 
Medidas individuais são importantes, mas devem ser contextualizadas com as demandas de melhorias da qualidade de vida da população, como o devido saneamento básico, pois esse fator está diretamente envolvido no ciclo de vida dos mosquitos. Moradores das comunidades afetadas pela epidemia de dengue em 1986 no Rio de Janeiro, representados por associações de moradores e outras entidades, criticaram as campanhas governamentais de incentivo às medidas individuais, argumentando que "as ações individuais que poderiam desenvolver, enquanto indivíduos, estavam limitadas pelo alcance das políticas públicas de saneamento que, historicamente têm seu alcance restrito aos setores mais abastados da população (OLIVEIRA; VALLA, 2001, p. 79).

A falta ou a precariedade de serviços como coleta de lixo e abastecimento de água desencadeiam condições favoráveis à formação de criadouros de mosquitos, pois criam demandas de armazenamento inadequado de lixo nas ruas e em terrenos diversos, bem como de água em recipientes, como galões e tonéis (OLIVEIRA; VALLA, 2001). No entanto, o problema do saneamento básico e a relação com focos de mosquitos não se restringem à cidade do Rio de Janeiro e nem aos anos de 1990, mas persiste atualmente em todo o Brasil. Além de ser um desrespeito aos direitos humanos, tem como consequência impactos sanitários como os ciclos de grandes epidemias transmitidas por mosquitos (FRANCO NETTO et al., 2017).

A garantia de saneamento básico efetivo é necessária para a promoção da saúde. $\mathrm{Na}$ luta por este direito, entre tantos outros, a população deve participar ativamente no planejamento de ações. Numa posição contra hegemônica, a concepção de Educação Popular em Saúde estimula a organização popular para assegurar o direito à saúde, valorizando o pensamento crítico, as ações coletivas e o envolvimento da comunidade para superação de desigualdades sociais (NESPOLI, 2016).

As ideias do educador Paulo Freire tiveram grande influência na organização e no desenvolvimento da educação popular (STOTZ, 1993; VASCONCELOS, 2004; BRANDÃO, 2006; NESPOLI, 2016) que se desenvolveu nos anos 1960 e 1970 no Brasil. Nespoli (2016, p. 48) esclarece que:

O trabalho de Paulo Freire foi muito importante para reforçar que os problemas sociais são resultado da divisão da sociedade em classes, divisão própria do capitalismo que permite que aqueles que detêm os meios de produção (e a riqueza) exerçam o poder político sobre a classe trabalhadora. Para Paulo Freire, a educação não deve estar a serviço da elite, ao contrário, deve ser uma forma de politizar a classe trabalhadora (ou as classes 
populares) para lutar por seus direitos e para buscar caminhos para a superação da desigualdade social e exploração humana.

Freire (1987) critica a unilateralidade na educação denominada bancária, na qual o conhecimento é transferido de um educador que detém os conhecimentos ou conteúdos, para educandos, considerados como acríticos e passivos, com função apenas de decorar conteúdos e não refletir de forma ampla. A educação popular, por outro lado, é construída por meio do diálogo:

Como todos nós estamos na condição de sujeitos, a educação popular se organiza em práticas horizontais e participativas, que nos conectam e nos colocam em diálogo para refletirmos sobre nossos problemas, necessidades, desejos. A educação popular em saúde se preocupa com a formação de sujeitos políticos, envolvidos na luta pela saúde, o que implica a luta por melhores condições de vida para todos e o questionamento profundo das iniquidades, injustiças sociais, econômicas e simbólicas. (NESPOLI, 2016, p. 50).

Nesta ótica, os educadores não devem transferir e nem impor ideias prontas, mas sim considerar o conhecimento dos educandos para aprenderem juntos. "A educação popular tem como um de seus pilares a relação dialógica, por meio da qual são conhecidos e respeitados os valores, experiências, crenças e cultura locais" (SCHALL; ASSIS; PIMENTA, 2015, p. 363). Sobre a dificuldade de promover diálogos e respeitar os conhecimentos dos alunos apresentada pelo educador bancário, Freire (1987, p. 37) esclarece:

Não pode perceber que somente na comunicação tem sentido a vida humana. Que o pensar do educador somente ganha autenticidade na autenticidade do pensar dos educandos, mediatizados ambos pela realidade, portanto, na intercomunicação. Por isto, o pensar daquele não pode ser um pensar para estes nem a estes imposto. Dai que não deva ser um pensar no isolamento, na torre de marfim, mas na e pela comunicação, em torno, repitamos de uma realidade.

Considerar o contexto social e promover diálogos entre população e profissionais da saúde/educação são medidas indispensáveis na busca de soluções efetivas para o problema. No entanto, a perspectiva educativa nas campanhas governamentais de combate ao mosquito Aedes aegypti ainda se baseia na concepção de educação sanitária, pois o foco está na necessidade de eliminar água parada e se proteger individualmente. Segundo Vasconcelos (2004), ainda há pouca articulação das campanhas de saúde feitas por grandes empresas de comunicação com o cotidiano de relação entre os profissionais de saúde e a população. 
É importante que profissionais relacionados à área de educação e que abordem temas de saúde e de meio ambiente, como os biólogos, reflitam de forma crítica sobre as diferentes concepções de educação. Afinal, no futuro profissional poderão desempenhar o papel de educadores seja como professores, pesquisadores, gestores, consultores, entre outras possibilidades. Ao dialogar com diferentes representantes da sociedade, o profissional poderá contribuir para manter os padrões atuais ou para a transformação da realidade, por isso deve refletir sobre a saúde a partir de enfoque amplo, não se restringindo aos aspectos biomédicos. Schall, Assis e Pimenta (2015, p. 373) refletem sobre lacunas na formação e sobre a necessidade de capacitação profissional em educação em saúde:

Poderia também estar mais presente nos cursos de graduação, incluída na formação dos profissionais da saúde e da educação. No entanto, são raros os currículos que incluem uma ou mais disciplinas que contemplem a educação em saúde. Trata-se de lacuna na formação desses profissionais que, após formados e participantes do mundo do trabalho, têm o papel de formar outros profissionais e crianças e jovens nas escolas do ensino básico. Sua formação incipiente em educação em saúde vai gerar problemas em sua atuação, a qual deixa de incorporar a dimensão social e cultural necessária à aquisição de atitudes e comportamentos em relação à saúde e prevenção de doenças.

Considerando a importância da dimensão educativa presente no trabalho do biólogo, no planejamento e na implementação de ações voltadas para a busca de soluções para a questão do controle do Aedes aegypti, se faz necessário discutir quais concepções de educação em saúde estão presentes durante o processo de formação. Cabe discutir se a formação do biólogo tem fomentado a perspectiva da Educação Popular em Saúde e de princípios como diálogo, consideração do contexto social e das desigualdades como parte do trabalho em saúde. Dessa forma, na futura prática, tais profissionais poderão considerar, além de aspectos ligados ao vetor e às doenças, também os sociais, como a urgência da garantia de saneamento básico para todos, sem exceção. Por isso, o objetivo do presente trabalho foi investigar se graduandos em Ciências Biológicas relacionavam medidas preventivas contra o referido vetor com as concepções de educação em saúde: educação popular e/ou educação sanitária, identificando limitações e demandas por maiores aprofundamentos sobre educação popular na formação dos futuros profissionais. 


\section{Metodologia}

Este trabalho é parte de uma tese de doutorado do Programa de Pós-Graduação em Ciências e Biotecnologia e foi aprovado pelo Comitê de Ética em Pesquisa da Universidade Federal Fluminense (UFF), parecer $n^{\circ}$ 3.302.318. A avaliação foi realizada com estudantes, de licenciatura e de bacharelado, de cursos de Ciências Biológicas da Universidade Federal Fluminense (UFF), de Niterói-RJ e da Universidade do Estado do Rio de Janeiro (UERJ), do polo CEDERJ Nova Friburgo. No geral, foram totalizados 139 participantes, sendo 98 alunos do primeiro período e 41 alunos do último ano (na UFF do $7^{\circ}$ período em diante e no CEDERJ do $9^{\circ}$ em diante).

Para investigar os conhecimentos dos participantes foi solicitada a elaboração de um texto no qual os graduandos deveriam se colocar no lugar de um Secretário de Saúde de uma cidade com surto de Dengue e propor estratégias para controlar doenças transmitidas pelo mosquito Aedes aegypti. Posteriormente, eles deveriam responder às seguintes questões discursivas: 1) "Você acha que estratégias educativas poderiam ajudar a controlar o problema das doenças transmitidas pelo mosquito Aedes aegypti. Se sim exemplifique"; 2) "Como um professor de Ciências/Biologia poderia contribuir como agente promotor de saúde numa comunidade escolar?".

$\mathrm{Na}$ análise dos resultados, foi observado se os alunos falaram sobre educação em saúde, mais especificamente as concepções de educação sanitária e de educação popular. Na classificação dos textos e das respostas, categorias foram sendo delineadas de acordo com a presença de elementos semânticos redigidos pelos alunos (BARDIN, 2011). Os conteúdos dos textos e de suas respostas às questões discursivas foram classificados em categorias e uma mesma resposta poderia contribuir para mais de uma categoria. As respostas das perguntas foram classificadas por dois diferentes avaliadores de forma consensual. $\mathrm{Na}$ análise dos textos, uma amostra de 60 foi categorizada por dois diferentes avaliadores e houve concordância de $90 \%$ entre eles. As discrepâncias foram analisadas e chegou-se a um consenso. Dessa forma, como a concordância foi alta, a análise continuou sendo feita por apenas um avaliador.

Considerando as diferenças entre as duas Universidades, um teste não paramétrico de Wilcoxson pareado comparou as frequências das respostas obtidas nas duas populações de participantes, encontrando alto grau de pareamento (coeficiente de Spearman de 0,9571) e ausência de diferenças significativas entre as duas amostras (UFF e UERJ, p=0,6333). Portanto, escolheu-se tratar todos os participantes com uma única amostra homogênea nas 
análises. O mesmo teste foi realizado para comparar o padrão de frequência de categorias de respostas obtidas com os alunos de períodos iniciais e finais. Os testes foram realizados com ajuda do software GraphPad Prisma 7.0, considerando um erro alfa $=5 \%$.

\section{Resultados}

Os textos elaborados pelos alunos sobre propostas de soluções para controlar doenças transmitidas pelo mosquito Aedes aegypti permitiram analisar o que espontaneamente os alunos pensariam como estratégias de controle. As diversas estratégias propostas pelos participantes foram organizadas em categorias que podem ser observadas no gráfico 1.

Gráfico 1 - Avaliação de conteúdo dos textos elaborados pelos alunos sobre propostas de soluções para controlar doenças transmitidas pelo mosquito Aedes aegypti

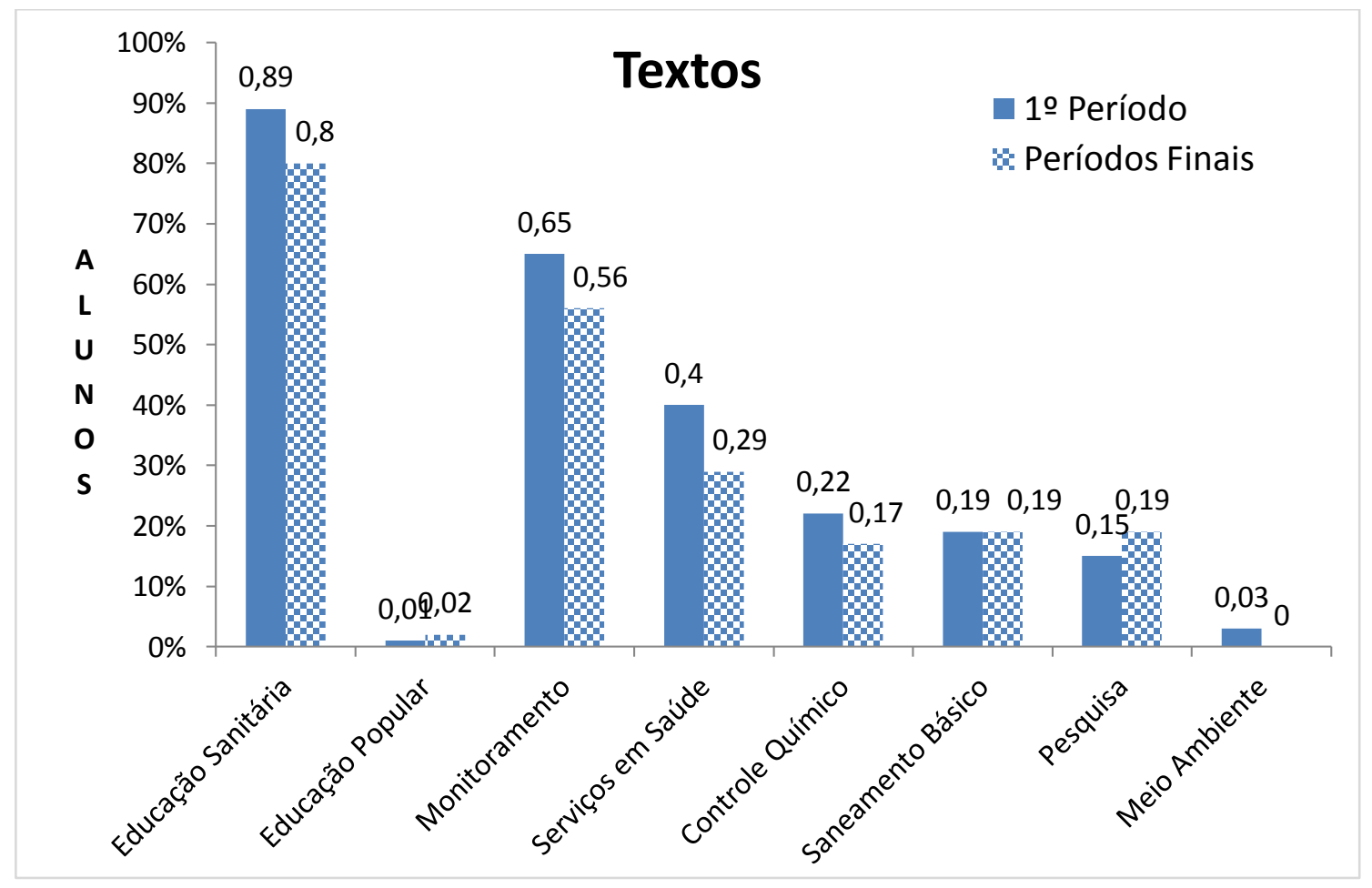

Fonte: Os autores (2019).

Obs.: As barras representam a frequência das principais categorias de elementos semânticos identificados no texto elaborado por graduandos de Ciências Biológicas de períodos iniciais $(n=98)$ e finais $(n=41)$ de duas universidades públicas, com o enunciado: "Imagine que você é Secretário de Saúde em uma cidade que está tendo um surto de Dengue e que dispõe de dinheiro para propor estratégias para controlar doenças transmitidas pelo mosquito Aedes aegypti. O que você faria? Escreva um texto de até 15 linhas apresentando uma proposta para o problema acima”.

É interessante observar que a maioria dos alunos falou sobre educação como uma estratégia para controlar doenças transmitidas pelo mosquito Aedes aegypti. No entanto, essas 
respostas foram classificadas, majoritariamente, na categoria educação sanitária (89\% do $1^{\circ}$ período e $80 \%$ dos períodos finais) e não de uma educação popular crítica, já que sugeriram a transmissão de informações, de forma vertical, por meio de palestras, campanhas e propagandas para ensinar medidas individuais de controle como eliminação de focos e uso de repelentes, de telas e de mosquiteiros.

Foi citado, ainda, o uso de materiais informando sobre prevenção: "Seria necessário educar a população local, ensinando-as como evitar a proliferação do mosquito transmissor, através de panfletos, visitas domésticas, mostrando os possíveis locais de ovos, como evitar e cuidar corretamente" (aluno, $1^{\mathrm{o}}$ período); "Como secretário de saúde acredito que investimento em materiais didáticos infantil seja de extrema importância, com sobra ou pouca verba, pois a curiosidade e atenção das crianças são pontos-chave para a consciência da população quanto aos focos da proliferação do mosquito" (aluno, $10^{\circ}$ período).

A Educação Popular foi citada por apenas um aluno do primeiro período, que escreveu sobre a participação da população.

Primeiro reuniria um grupo ou comitê para conversar e analisar a cidade que está sendo abordada e dentro dessas reuniões proporia diferentes tipos de atividades com a participação da população. Dentre elas, primeiro reuniria toda a população ou o máximo de pessoas e faria um debate sobre a dengue e conscientizar o máximo de pessoas, logo depois faria prevenção e cuidados com a dengue [...]. (Aluno, $1^{\circ}$ período).

No entanto, na mesma resposta foi destacada a importância de conscientizar as pessoas para prevenir focos do mosquito e, por isso, foi incluída também na categoria Educação Sanitária.

[...] Tendo dinheiro pagaria cada agente de saúde para fazer atividades nas escolas da cidade do fundamental ao médio, também proporia gincanas sobre os cuidados com a dengue e como evitá-la e por fim iria fazer visitas em algumas casas para verificar se há dengue ou ovos de dengue e continuar a campanha, tipo a semana ou o mês da dengue. (Aluno, $1^{\circ}$ período).

Nos períodos finais, apenas um aluno se referiu à educação popular, no seguinte trecho:

Acredito que não apenas práticas pontuais devam ser incentivadas, mas sim que o estado faça uma reforma educacional que tenha como objetivo um ensino de fato crítico para o que os alunos aprendam em sala, reflitam em suas vidas e para a sociedade e não apenas que seja um compilado de conteúdos que precisam ser decorados. (aluno, $10^{\circ}$ período). 
A segunda categoria de resposta mais prevalente se referiu ao monitoramento, seja por meio de mapeamento das áreas com maior incidência de focos ou do trabalho de fiscalização por voluntários e diferentes profissionais como agentes de saúde, de endemia, do exército, da Comlurb, ambientais e federais: "Enviaria agentes federais mensalmente para solicitar permissão de entrada nas casas dos moradores para verificar se tudo está sendo feito corretamente na prevenção e caso não os agentes conversariam com os moradores e fariam junto com eles os procedimentos" (aluna, $1^{\mathrm{o}}$ período); “[...] dando sequência ao trabalho, seria envolvido na situação os agentes sanitários locais, que fariam uma abordagem nos bairros, esclarecendo as dúvidas e fiscalizando as casas" (aluna, $10^{\circ}$ período).

Em Serviços de Saúde, foram mencionadas medidas como vacinação em massa, distribuição de repelentes, telas e medicamentos, melhorias no atendimento em hospitais e postos e diagnósticos mais rápidos. Também apontaram a necessidade de aumento de profissionais na área de saúde e investimento na atenção à saúde: "Eu contrataria agentes de saúde para visitar as casas da região para que eles fizessem uma análise de onde estavam vindo os focos de reprodução do mosquito causado pelo acúmulo de água parada" (aluna, $1^{\circ}$ período); “Também aumentaria o número de médicos nas unidades de saúde, com o intuito de auxiliar o maior número de pessoas doentes possível” (aluno, $8^{\circ}$ período).

O Controle Químico também foi muito lembrado pelos discentes que se referiram aos carros de fumacê: "Tratando-se de Aedes aegypti, em específico, acredito (suposição) que as medidas mais eficazes pelo custo/benefício seria o uso dos carros de 'fumacê' (aquelas caminhonetes que espalham um inseticida como uma fumaça branca)" (aluno, $7^{\circ}$ período). E também a substâncias para impedir proliferação, possivelmente se referindo aos larvicidas: “Tais agentes aplicariam substâncias tóxicas para o Aedes aegypti, mas não para as pessoas nas caixas d'água, barris, poços e quaisquer outros locais ou recipientes nos quais os mosquitos pudessem se proliferar" (aluna, $1^{\circ}$ período).

O Saneamento Básico apareceu apenas como a quinta categoria e lembrada por apenas $19 \%$ dos alunos. Os graduandos sugeriram medidas como limpeza das ruas, tratamento de esgoto, eliminação de esgoto a céu aberto e tratamento e abastecimento de água. Também citaram o descarte inadequado de lixo. "Atuaria na eliminação de ditos 'lixões', afinal são áreas propícias para a proliferação do mosquito, devido aos acúmulos de água parada e ausência de cuidados com o local" (aluna, $1^{\circ}$ período). Além dos lixões, mencionaram cuidados com terrenos baldios: “Além disso, trabalharia para que não só a população evitasse focos de ocorrência do Aedes aegypti, mas também para locais públicos, inclusive os abandonados, tivessem o mínimo de tratamento nesse sentido" (aluna, $8^{\circ}$ período). 
Pesquisas foram lembradas no sentido de melhorar o controle químico, de investigar novas formas de prevenção e realizar estudos sobre fisiologia do inseto. Também foram mencionadas pesquisas na área de biotecnologia: "investiria em pesquisa para criar uma espécie de Aedes aegypti imune às doenças, para que eles fossem substituindo os não imunes, como medida de longo prazo" (aluna, $1^{\mathrm{o}}$ período). E muitos escreveram sobre desenvolvimento de vacinas: "E aplicar as pesquisas desenvolvidas nas universidades para que a população possa usufruir desse investimento realizado em especial no desenvolvimento de vacinas" (aluna, $8^{\circ}$ período).

Algumas repostas dos alunos foram incluídas na categoria Meio Ambiente, pois escreveram sobre evitar (ou acabar com) o desmatamento: “[...] e propor um planejamento de acabar com o desmatamento e cortes da vegetação, visto que isso leva os mosquitos às cidades, já que acabam com o meio onde eles vivem" (aluna, $1^{\circ}$ período).

Na primeira questão, foi perguntado "Você acha que estratégias educativas poderiam ajudar a controlar o problema das doenças transmitidas pelo mosquito Aedes aegypti? Se sim, exemplifique". A maioria dos participantes (99\% dos períodos iniciais e $98 \%$ dos finais) afirmou que estratégias educativas poderiam ajudar no controle das doenças transmitidas pelo Aedes aegypti. Apenas um aluno, em cada grupo, respondeu de forma negativa, sendo que um deles justificou alegando como se não valesse o esforço "geralmente parte da população não faz a sua parte e para ter o controle todos teriam que ajudar" (aluno, $10^{\circ}$ período).

Dentre as justificativas para as respostas afirmativas, as estratégias educativas relacionadas à prevenção, sobretudo para eliminação de criadouros do mosquito, foram as que apresentaram maior percentual de respostas nos dois grupos pesquisados $\left(71 \%\right.$ no $1^{\circ}$ período e $61 \%$ nos finais). Outros assuntos sugeridos como alvos nas ações educativas foram conscientização e multiplicação de informações. Conscientização representou $29 \%$ das respostas dos alunos do $1^{\circ}$ período e $34 \%$ dos finais, que recomendaram medidas para estimular mudanças na forma de pensar e agir em relação ao problema, como na reposta: “A partir do momento em que se tem o conhecimento do assunto as atitudes mudam, existe a conscientização" (aluna, $9^{\circ}$ período). Alguns participantes ( $8 \%$ do $1^{\circ}$ período e $7 \%$ dos finais) relataram a importância das estratégias educativas para a multiplicação de informações para os familiares e outros membros da comunidade na qual os alunos das escolas estão inseridos.

Nessa primeira questão, foram identificadas categorias sobre a concepção de educação (sanitária ou popular). No entanto, algumas respostas foram vagas e ficaram na categoria sem classificação como esta: "Sim, com ações educativas de um modo mais descontraído poderia obter um resultado mais significativo" (aluna, $1^{\circ}$ período). Também foram identificadas 
categorias sobre a forma de ensinar (transferência de informações e estratégias dinâmicas), conforme apresentado no Gráfico 2.

A Educação Sanitária teve destaque e entre o total de alunos que escreveram sobre essa concepção, $57 \%$ ( $1^{\circ}$ período) e $44 \%$ (finais). Também se referiram à transferência de informações para ensinar formas de prevenção, como nesse relato: "Sim, passando a informação que o ciclo reprodutivo do mosquito tem fase larval em água parada, pessoas podem assim evitar água parada, evitando a proliferação" (aluno, $1^{\circ}$ período).

Nessa questão, a Educação Popular não foi detectada no primeiro período e teve representação por apenas um aluno do $8^{\circ}$ período. $\mathrm{O}$ estudante ressaltou a importância da responsabilidade social e que a solução não deve ser individual: "Não vejo como uma solução do problema, pois permite apenas a formação de uma responsabilidade individual e não social. Seria importante a atuação do poder público".

Gráfico 2 - Avaliação das categorias que emergiram de respostas dos graduandos de Ciências Biológicas à questão sobre a importância de estratégias educativas no controle do problema das doenças transmitidas pelo Aedes aegypti.

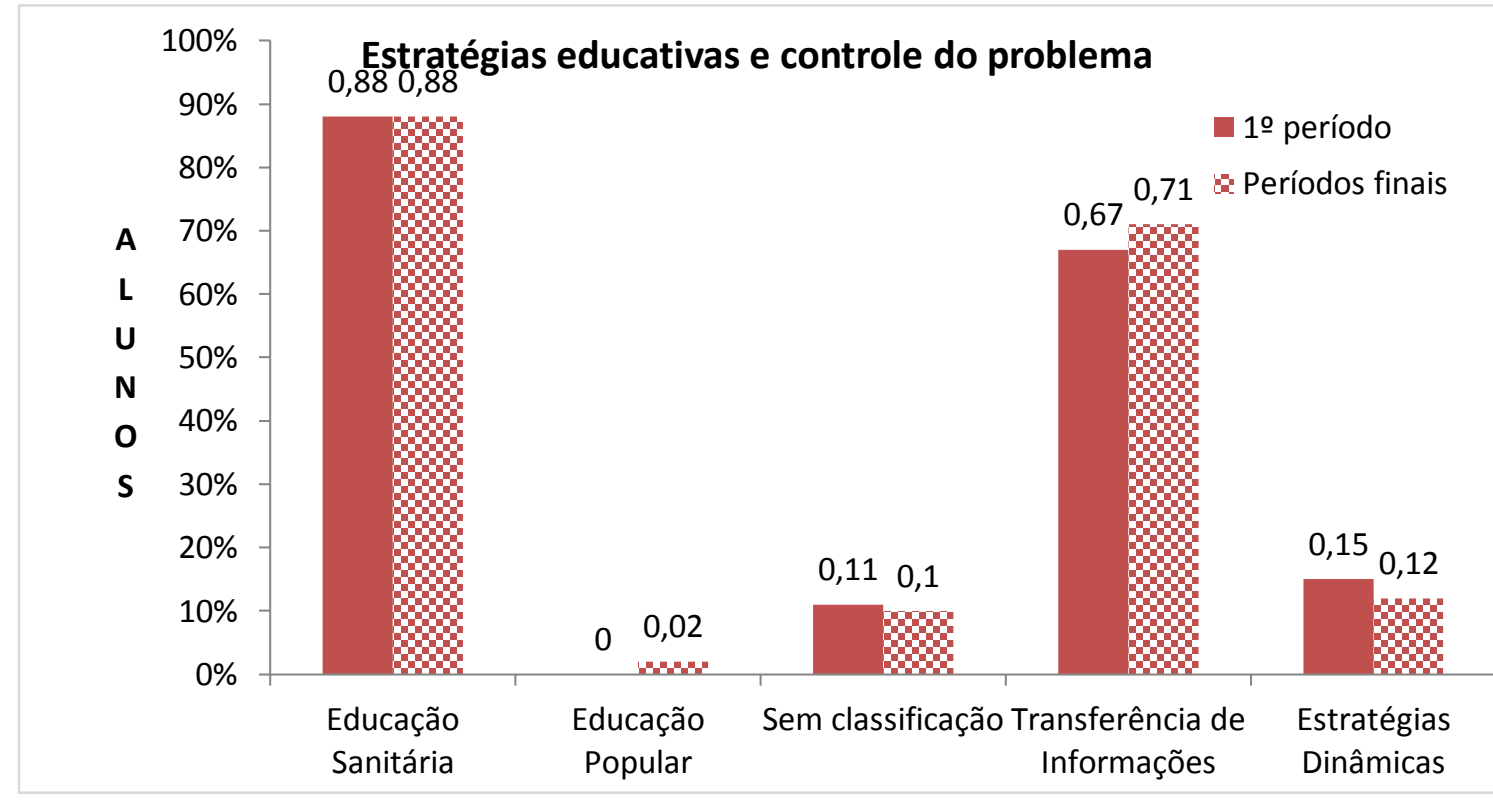

Fonte: Os autores (2019).

Obs.: As barras representam a frequência das principais categorias de elementos semânticos identificados nas respostas de graduandos de Ciências Biológicas de períodos iniciais $(n=98)$ e finais $(n=41)$ de duas universidades públicas à questão: "Você acha que estratégias educativas poderiam ajudar a controlar o problema das doenças transmitidas pelo mosquito Aedes aegypti. Se sim, exemplifique".

A educação apresentada pela maioria dos alunos foi como transferência de informações. Surgiram, nas respostas, os verbos instruir, desmitificar, demonstrar, orientar, 
explicar e ensinar para se referir ao papel do professor ou do agente de saúde na prevenção. Metodologias como aulas, palestras e campanhas, e a utilização de materiais como cartilhas, cartazes, panfletos e vídeos foram citados para auxiliar a passar informações. Nessa categoria, também foram incluídas respostas que se referiam aos alunos como aqueles que não têm conhecimento ou apresentam conceitos errados, por isso necessitam ser informados: "Sim, pois muitas pessoas não sabem de coisas básicas que podem ajudar a evitar o mosquito da dengue" (aluno, $1^{\circ}$ período); "Sim. Através da informação adequada é possível conscientizar as pessoas quanto a possíveis formas de prevenção" (aluno, $9^{\circ}$ período).

Estratégias dinâmicas, como peças teatrais, jogos, mutirão de limpeza, debates e aulas práticas para identificar focos, foram citadas. No entanto, em nenhuma resposta foi sugerida uma educação mais dialógica com o aluno.

Nas respostas à questão "Como um professor de Ciência/Biologia poderia contribuir como agente promotor de saúde numa comunidade escolar?", foi observado o tipo de papel atribuído ao professor. Quatro categorias foram detectadas: transmissor, mediador, multiplicador e conscientizador (Gráfico 3).

Gráfico 3 - Avaliação das principais categorias de respostas que emergiram sobre o papel do professor de Ciências/Biologia na promoção de saúde

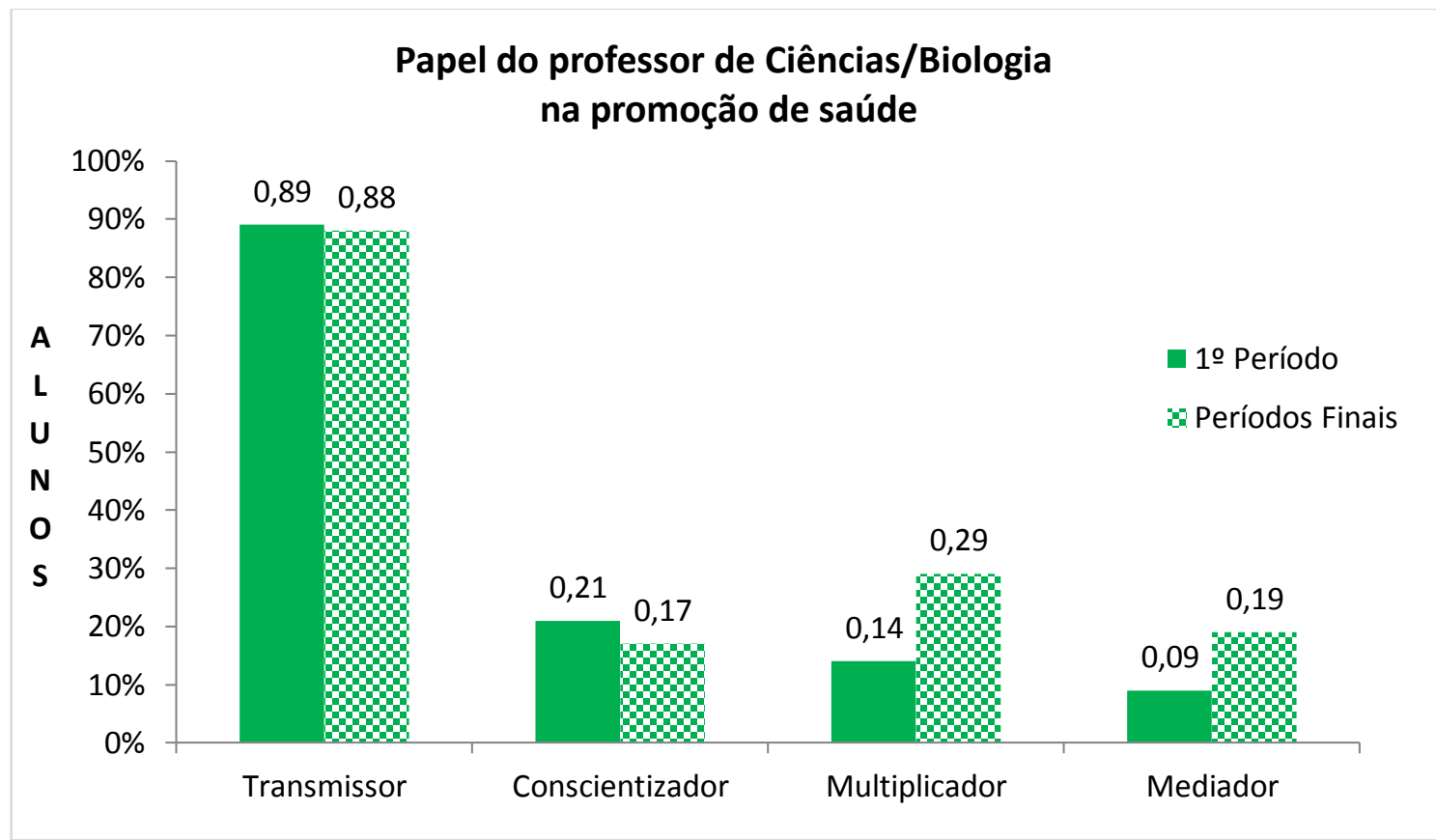

Fonte: Os autores (2019).

Obs.: As barras representam as frequências das principais categorias de elementos semânticos identificados nas respostas de graduandos de Ciências Biológicas de períodos iniciais $(n=98)$ e finais $(n=41)$ de duas universidades públicas à questão "Como um professor de Ciência/Biologia poderia contribuir como agente promotor de saúde numa comunidade escolar?’. 
Os resultados para a segunda questão mostram que, tanto nos períodos iniciais quanto nos finais, preponderou o papel do professor como detentor de conhecimentos que deveriam ser transferidos aos alunos. Como transmissor, o professor é responsabilizado por passar informações e conhecimentos sobre diversos assuntos como o ciclo de vida do mosquito: " $\mathrm{O}$ professor poderia mostrar o processo de nascimento do mosquito...” (aluno, $10^{\circ}$ período). Formas de prevenção: “O professor de ciências/Biologia poderia ensinar aos alunos quais as formas de evitar a manifestação do vetor/doença em suas casas; como retirar vasilhas e brinquedos que pudessem acumular água dos quintais..." (aluno, $1^{\circ}$ período). E sobre identificação de sintomas e como tratar doenças: "Poderia instruir alunos e identificar sintomas de doenças e formas de prevenção e tratamento" (aluno, $1^{\circ}$ período).

$\mathrm{Na}$ categoria conscientizador, em muitas respostas, a palavra conscientização foi recorrente, assim como a noção de que, com a sensibilização, existe a possibilidade de mudar atitudes: "Realizando trabalhos de conscientização com seus alunos" (aluna, $1^{\circ}$ período).

Multiplicador se referiu à atuação docente para divulgação de informações além dos muros da escola, ou seja, extensão para a comunidade: "Transmitindo informação e educação sobre as doenças e as maneiras de evitá-las, fazendo com que o aluno transmita isso para os pais e eles repassem para outras pessoas, criando uma corrente do bem” (aluno, $1^{\circ}$ período).

$\mathrm{Na}$ função de mediador, o profissional foi descrito como capaz de propor diálogo, estimular debates e pensamentos críticos para formar cidadãos ativos ou transformar a realidade. Os trechos a seguir mostram alguns exemplos de respostas incluídas na categoria de mediador: "Discutindo questões de saúde pública em sala de aula e dando ênfase ao poder das ações individuais..." (aluno, $1^{\circ}$ período); "Através de técnicas integradas e dinâmicas que permitissem aos alunos enxergar a importância do debate e se aproximar disso" (aluno, $7^{\circ}$ período); “Com atividades que não só mostrem como é a doença e como se prevenir, mas que também contextualizem os alunos em qual ambiente eles vivem e como transformá-lo de forma ativa. Incentivo do governo!!!” (aluno, $10^{\circ}$ período).

É importante salientar que as frequências de categorias identificadas no texto e as respostas para as questões discursivas de alunos de períodos iniciais $(n=98)$ e finais $(n=41)$ não apresentaram diferenças significativas em seu padrão geral $(\mathrm{p}<0.05)$ quando foram comparadas em um teste de correlação não paramétrico. 


\section{Discussão}

A predominância da concepção hegemônica de educação sanitária demonstrou que o enfoque biomédico vigora entre os participantes dessa pesquisa, da mesma forma como Nespoli (2006) relata ocorrer desde o início do século 20. De um modo geral, as respostas foram direcionadas a medidas de autocuidado e a necessidade de mudança de comportamentos individuais para evitar doenças. Poucos mencionaram fatores sociais, culturais e políticos que são indispensáveis para uma compreensão holística do tema saúde (BUSS; PELLERGRINI FILHO, 2006).

O destaque dado à demanda de monitoramento e fiscalização por agentes de saúde e outros profissionais para efetivar medidas profiláticas remete ao modelo de participação descrito por Rangel (2008), segundo o qual a participação das pessoas representa uma atitude de obediência às autoridades sanitárias.

O uso de inseticidas e larvicidas, bem como o desenvolvimento de novos produtos para controle químico foram recomendados pelos graduandos, revelando que as medidas propostas para resolver os problemas causados por mosquitos Aedes aegypti continuam semelhantes às propostas desde as primeiras epidemias de dengue, como relatam Oliveira e Valla (2001). No entanto, hoje é sabido que o controle químico deve ser usado com cautela e como parte de um manejo integrado devido ao rápido crescimento de resistência na população de mosquitos e aos diversos problemas relacionados à saúde e ao meio ambiente (MANJARRES-SUAREZ; OLIVERO-VERBEL, 2013; OLIVEIRA; CALEFFE; CONTE, 2017).

Apesar de praticamente todos os participantes da pesquisa considerarem a importância das estratégias educativas, houve a predominância da ideia de transmissão de informações de forma verticalizada com o objetivo de estimular atitudes individuais contra a formação de criadouros, reforçando a prevalência da concepção de educação sanitária entre os participantes. Essa visão dos graduandos está de acordo com o modelo explicativo que é focado no vetor e no combate aos criadouros (RANGEL, 2008).

A transferência das instruções preventivas, por meio de materiais como cartilhas e palestras, também foi recomendada, como se as informações pudessem motivar os alunos e desencadear mudanças de comportamento, o que está de acordo com o modelo de prevenção que é voltado para campanhas, visando instruir a população para esse combate (RANGEL, 2008). Schall, Assis e Pimenta (2015) analisaram materiais informativos/educativos e concluíram que ferramentas com base na transmissão de informações resultam em pouco interesse e impacto. A valorização da prevenção de doenças e conscientização também foi 
observada por Zancul e Gomes (2011) que verificaram a concepção de estudantes de Licenciatura em Ciências Biológicas sobre a importância dos temas de educação em saúde na escola. E ao investigar a concepção de professores de Ciências e Biologia sobre educação em saúde, Zancul e Costa (2012) mostram que o entendimento sobre a importância da transmissão de conhecimentos sobre saúde para prevenir doenças está presente também entre biólogos já formados.

Na presente investigação, muitas vezes os alunos se referiram à conscientização como a necessidade de aquisição de conhecimentos para mudar pensamentos e atitudes relacionados ao problema da dengue. Essa concepção pode ser classificada dentro do modelo de comunicação e educação proposto por Rangel (2008) que representa usar a transmissão de informações para desencadear mudanças de hábitos e comportamentos. Diversos programas educativos de controle da dengue consideram, geralmente de forma equivocada, ser suficiente focar na conscientização para desencadear mudanças de comportamento e, assim, garantir a prevenção adequada (JARDIM; SCHALL, 2015). No entanto, apenas ter conhecimento do assunto não garante mudanças; muitas pessoas, por exemplo, não têm condições sociais concretas para colocar em prática a ação recomendada.

Considerar que as atitudes das pessoas e o desconhecimento de medidas de autocuidado geram doenças é uma forma de culpar as vítimas, pois enfatiza a saúde como uma escolha individual e não um direito social (STOTZ, 1993). A preocupação com a garantia de direitos sociais, relacionados aos problemas causados por Aedes aegypti infectados esteve presente em apenas algumas respostas por meio de temas como políticas públicas para melhorias na saúde, meio ambiente e saneamento básico. Apesar dos direitos de acesso a serviços de saúde, ao meio ambiente equilibrado e ao saneamento básico serem assegurados na Constituição Brasileira (BRASIL, 1988), não são oferecidos a todos de forma efetiva. A participação popular é indispensável na luta por melhorias nos serviços públicos oferecidos. E a educação pode contribuir para a aceitação dos padrões atuais de atenção à saúde ou para motivar transformações na realidade.

Apesar da concepção de educação popular ter sido pouco expressiva nos resultados, é importante registrar que alguns participantes sugeriram a participação dos alunos e da população em geral em debates visando à transformação da realidade, o que indica a compreensão que a busca de soluções se relaciona à problematização do assunto. Para Stotz (1993), a problematização, no enfoque da educação popular, envolve pensar questões de modo indissociável dos recursos disponíveis na busca de soluções. Logo, é preciso conhecer a realidade da comunidade e entender a importância da contextualização com o ambiente no 
qual a população está inserida para se pensar soluções para o problema da dengue. A distância da realidade é destacada por Ballester et al. (2005) que verificaram a pouca efetividade de campanhas com o uso de linguagem técnica em programas de prevenção em uma localidade onde o serviço de coleta de lixo não estava disponível, havia lixões próximos às residências e o saneamento básico era precário. Assis, Schall e Pimenta (2013) também observaram a falta da contextualização com a realidade social e um forte cunho biomédico nas análises que realizaram das representações visuais sobre a dengue em livros didáticos e materiais impressos.

De acordo com Nespoli (2016), para assegurar o direito à saúde, é preciso que questões sejam debatidas de forma crítica, possibilitando o planejamento de ações. Estratégias educativas interativas podem ser desenvolvidas com a intenção de estimular reflexões críticas e embasar debates que contribuam para mudanças sociais. Nas conversas, o pensamento de um não deve ser imposto a outro (FREIRE, 1987). No entanto, diálogos e interações também podem ser conduzidos apenas com o intuito de reproduzir valores hegemônicos.

Entre os alunos que escreveram sobre estratégias educativas dinâmicas, nenhum aluno pensou em usar as metodologias para estimular reflexões e ações para tornar a sociedade mais justa. As sugestões de atividades, como jogos e peças de teatro, não foram mencionadas no sentido de promover discussões coletivas para traçar planos em busca de soluções, mas de motivar os participantes para executar medidas ligadas à educação sanitária, como instruções às mudanças de atitudes, visando repelir mosquitos e evitar água parada.

Embora alguns tenham demonstrado que o ensino deve priorizar menos a memorização e mais o ensino crítico, em harmonia com o pensamento de Freire (1987), a maioria dos alunos atribuiu ao professor o papel de detentor de conhecimentos a serem transferidos a receptores passivos e acríticos. No entanto, o professor deve estabelecer um diálogo horizontal com os educandos, atuando como um mediador capaz de estimular discussões críticas que considerem os conhecimentos e a realidade dos envolvidos e que permitam desencadear transformações na sociedade. Mesmo com a pouca representatividade da educação popular, o professor como mediador foi citado pelos alunos. Apesar de não apresentarem base teórica sólida sobre a referida concepção de educação, valorizam os professores que ensinam de forma não autoritária, mas sim dialogada, aprendendo à medida que ensinam, conforme Freire (1987) pensava sobre a função do professor.

O enfoque predominante encontrado no presente trabalho na educação sanitária na concepção dos alunos faz refletir sobre a necessidade de maiores aprofundamentos sobre educação popular na formação de Biólogos. Zancul e Gomes (2011) analisaram o currículo de 
um Curso de Licenciatura em Ciências Biológicas e verificaram que as disciplinas não abordavam o tema educação em saúde na escola. Vasconcelos (2004) afirma que não há um direcionamento para ações pedagógicas na formação de profissionais de saúde que considerem a participação popular no sentido de transformar o sistema de saúde. Para o autor, o objetivo nos cursos é formar para promover a saúde, reproduzindo ações educativas normatizadoras e centradas em medidas individuais e em campanhas de massa. Schall, Assis e Pimenta (2015) corroboram essa visão e sugerem que a educação em saúde poderia estar mais presente nos currículos de graduandos, para que os futuros profissionais de educação e saúde possam estar aptos a relacionar saúde aos aspectos social e cultural, e não somente aos aspectos biomédicos. Gomes (2009) também sugere que a educação em saúde deva estar presente em cursos universitários em geral, mas especialmente nos de formação de professores, seja por meio de uma disciplina específica ou da inserção do tema em diferentes disciplinas ou em atividades extracurriculares.

Considerando a importância da dimensão educativa presente no trabalho do biólogo e seu papel na promoção da saúde, é fundamental que essa lacuna em sua formação seja repensada, não só pela inserção de disciplinas de educação popular em saúde, mas de forma integrada e transversal ao longo de sua formação, e também por meio de projetos de extensão nos quais possam ser vivenciadas práticas horizontais que valorizem o conhecimento de todos os envolvidos.

\section{Considerações finais}

Nessa pesquisa, a maioria dos alunos, tanto dos períodos iniciais quantos dos finais, pensou em soluções para a questão do controle do Aedes aegypti sob o enfoque da educação sanitária. De modo geral, os participantes demonstram não ter refletido profundamente sobre a importância da educação popular durante o ensino médio e nem mesmo ao longo da graduação, como sugerido pela grande similaridade nas opiniões expressas entre alunos do primeiro e dos últimos períodos.

Tais considerações remetem à necessidade de valorizar estudos aprofundados sobre Educação Popular em Saúde na formação de biólogos. Para isso, sugere-se o desenvolvimento de pesquisas para o planejamento e a execução de reformulações no currículo dos cursos de graduação em Ciências Biológicas, para que a Educação Popular em Saúde seja discutida não apenas em uma disciplina específica, mas de forma integrada e transversal, e vivenciada em projetos de extensão. 
Durante o processo de formação, o biólogo que conhecer e experimentar a perspectiva da Educação Popular em Saúde poderá, na sua atuação profissional, pensar a saúde de forma ampla e assim estabelecer relações horizontais com a população, incentivando a participação em decisões importantes para a comunidade onde esteja inserido.

\section{Referências}

ASSIS, S. S.; SCHALL, V. T.; PIMENTA, D. N. As representações visuais da dengue em livros didáticos e materiais impressos. Revista Eletrônica de Comunicação, Informação \& Inovação em Saúde, Rio de Janeiro, v. 7, n. 3, p.1-21, set. 2013. Disponível em: https://www.reciis.icict.fiocruz.br/index.php/reciis/article/view/504/2005. Acesso em: 26 fev. 2020.

BALLESTER, L. M. et al. Experiência de grupos colaborativos para educação e saúde e prevenção em dengue. In: ENCONTRO NACIONAL DE PESQUISA EM EDUCAÇÃO EM CIÊNCIAS, 3., 2005, Atas [...]. Bauru: ABRAPEC, 2005. p. 1-12.

BARDIN, L. Análise de conteúdo. São Paulo: Edições 70, 2011.

BRANDÃO, C. R. O que é educação popular. São Paulo: Brasiliense, 2006.

BRASIL. [Constituição (1988)]. Constituição da República Federativa do Brasil. Brasília, DF: Senado Federal, 1988.

BRASIL. Ministério da Saúde. Secretaria de Vigilância em Saúde. Monitoramento dos casos de arboviroses urbanas transmitidas pelo Aedes (dengue, chikungunya e zika). Boletim Epidemiológico, Brasília, v. 50, n. 22, 2019. Disponível em: https://portalarquivos2.saude.gov.br/images/pdf/2019/setembro/11/BE-arbovirose-22.pdf Acesso em: 22 fev. 2020.

BRASIL. Ministério da Saúde. Secretaria de Vigilância em Saúde. Monitoramento dos casos de arboviroses urbanas transmitidas pelo Aedes (dengue, chikungunya e zika). Boletim Epidemiológico, Brasília, v. 51, n. 7, 2020. Disponível em:

https://portalarquivos2.saude.gov.br/images/pdf/2020/fevereiro/19/Boletim-epidemiologicoSVS-07.pdf . Acesso em: 22 fev. 2020

BUSS, P. M.; PELLEGRINI FILHO, A. Iniquidades em saúde no Brasil, nossa mais grave doença: comentários sobre o documento de referência e os trabalhos da Comissão Nacional sobre Determinantes Sociais da Saúde. Cadernos Saúde Pública, Rio de Janeiro, v. 22, n.9, p. 2.005-2.008, set. 2006. Doi: 10.1590/S0102-311X2006000900033.

FRANCO NETTO, G. et al. Vigilância em saúde brasileira: reflexões e contribuição ao debate da $1^{\text {a }}$ Conferência Nacional de Vigilância em Saúde. Ciênc. saúde coletiva [online], Rio de Janeiro, v. 22, n. 10, p. 3.137-3.148, 2017. Doi: 10.1590/1413812320172210.18092017.

FREIRE, P. Pedagogia do oprimido. 17. ed. Rio de Janeiro: Paz e Terra, 1987. 
GOMES, J. P. As Escolas Promotoras de Saúde: uma via para promover a saúde e a educação para a saúde da comunidade escolar. Educação, Porto Alegre, v. 32, n. 1, p. 84-91, jan.-abr. 2009.

JARDIM, J. B.; SCHALL, V. T. Participação social no controle da dengue: a importância de uma mudança conceitual. In: VALLE, D. (org.). Dengue: teorias e práticas. Rio de Janeiro: Editora Fiocruz, 2015. p. 317-338.

MANJARRES-SUAREZ, A.; OLIVERO-VERBEL, J. Chemical control of Aedes aegypti: a historical perspective. Revista Costarricense Salud Pública, San José, v. 22, n. 1,

NESPOLI, G. Da educação sanitária à educação popular em saúde. In: BORNSTEIN, V. J. (org.). Curso de aperfeiçoamento em educação popular em saúde: textos de apoio. Rio de Janeiro: EPSJV, 2016. p. 47-51.

OLIVEIRA, R. M.; VALLA, V. V. As condições e as experiências de vida de grupos populares no Rio de Janeiro: repensando a mobilização popular no controle da dengue. Cad. Saúde Pública, Rio de Janeiro, n. 17 (Suplemento), p. 77-88, 2001. Doi: 10.1590/S0102311X2001000700016.

OLIVEIRA, S. R.; CALEFFE, R. R. T.; CONTE, H. Revista Eletrônica em Gestão, Educação e Tecnologia Ambiental, Santa Maria, v. 21, n. 3, p. 240-247, set-dez. 2017. p. 68-75, jan.-jun. 2013. Doi: 10.5902/2236117029795.

RANGEL, M. L. Dengue: educação, comunicação e mobilização na perspectiva do controlepropostas inovadoras. Interface: Comunicação, Saúde, Educação, Botucatu, v. 12, n. 25, p. 433-441, 2008. Doi: 10.1590/S1414-32832008000200018.

SCHALL, V. T.; ASSIS, S. S.; PIMENTA, D. N. Educação em saúde como estratégia no controle integrado da dengue: reflexões e perspectivas. In: VALLE, D. (org.). Dengue: teorias e práticas. Rio de Janeiro: Editora Fiocruz, 2015. p. 357-380.

STOTZ, E. N. Enfoques sobre educação e saúde. In: VALLA, V. V.; STOTZ, E. N. (org.). Participação popular, educação e saúde: teoria e prática. Rio de Janeiro: Relume-Dumará; 1993. p. 11-22.

VASCONCELOS, E. M. Educação popular: de uma prática alternativa a uma estratégia de gestão participativa das políticas de saúde. Physis, Rio de Janeiro, v. 14, n. 1, p. 67-83, 2004. Doi: $10.1590 / \mathrm{S} 0103-73312004000100005$.

ZANCUL, M. S., COSTA, S. Concepções de professores de ciências e de biologia a respeito da temática educação em saúde na escola. Experiências em Ensino de Ciências, Cuiabá, v. 7, n. 2, p. 67-75, set. 2012.

ZANCUL, M. S., GOMES, P. H. M. A formação de licenciandos em Ciências Biológicas para trabalhar temas de educação em saúde na escola. Repec, Niterói, v. 4, n.1, p.49-61, abr.

2011. Doi: 10.22409/resa2011.v4i1.a21097.

Submetido em 20 de março de 2020.

Aprovado em 7 de julho de 2020. 